\title{
A versatile model for tritium transfer from atmosphere to plant and soil
}

\author{
A. Melintescu and D. Galeriu \\ National Institute for Physics and Nuclear Engineering "Horia Hulubei", Life and \\ Environmental Physics Department, 407 Atomistilor St., Bucharest-Magurele, POB MG-6, \\ 077125, Romania
}

\begin{abstract}
The need to increase the predictive power of risk assessment for large tritium releases implies a process level aproach for model development. Tritium transfer for atmosphere to plant and the conversion in organically bound tritium depend strongly on plant characteristics, season, and meteorological conditions. In order to cope with this large variability and to avoid also, expensive calibration experiments, we developped a model using knowledge of plant physiology, agrometeorology, soil sciences, hydrology, and climatology. The transfer of tritiated water to plant is modelled with resistance approach including sparce canopy. The canopy resistance is modelled using Jarvis-Calvet approach modified in order to directly use the canopy photosynthesis rate. The crop growth model WOFOST is used for photosynthesis rate both for canopy resistence and formation of organically bound tritium, also. Using this formalism, the tritium transfer parameters are directely linked to known processes and parameters from agricultural sciences. The model predictions for tritium in wheat are closed to a factor two to experimental data without any calibration. The model also is tested for rice and soybean and can be applied for various plants and environmental conditions. For sparce canopy the model uses coupled equations between soil and plants.
\end{abstract}

\section{INTRODUCTION}

There are three phases in the dynamics of tritium in SVAT (soil-vegetation- atmosphere transport). The first one treats the period of active deposition when the cloud of tritiated water travels the study area and the atmospheric concentration is the driving source of tritium. The last one starts few days after cloud passage, when the soil water tritium is the driving force. The middle stage takes care of the reemission of HTO from vegetation and surface soil into the atmosphere, a fast process immediately after cloud passage, slowing down later. The active and transition phase are sensitive to actual meteorological parameters (sunshine, humidity, temperature, and rainfall) as were as on plant physiological characteristics and growth stage. In the later stage the processes to be considered are movement of tritiated water in rooth soil, depth distribution of roots, evapotranspiration and plant photosynthesis. This can be modeled with a slow dynamics, using climatic data and approximate dynamics of some plant parameters. After an atmospheric dry deposition episode the tritiaded water concentration in plant is decresing fast, while the OBT concentration in whole plant will decrease very slow but will be translocated to storage plant parts. For crops harvested one time in the year, most of tritium in the harvested plant will be in form of OBT, while for continously harvestd plants as grass and leafy vegetable, in the first few days after the accident, the concetration of HTO is high. An operational model must include both situations under various agrometeorological conditions. The well-known model UFOTRI was built to cope with these requirements and senitivity and uncertainty has been analysed [1] showing reliability for maximum exposed individual (worse case) as required for a facil design and licencing. This study and discussions in the IAEA-EMRAS tritium group 
pointed also that some processes can be of variable importance in a different context and that more research is needed for case application in accident prepardness and management. Photosynthesis and partitioning of newly formed dry matter are basic processes driving tritium transfer. We have demonstrated previously [2] that the WOFOST crop growth model: (i) gives predictions comparable with more complex specific species photosynthesis models; (ii) can describe C3 and C4 plant growth under various climatic conditions. The application of the WOFOST crop model to derive tritium transfer from atmosphere to plants is reported here with an extension of the SVAT model for tritium including sparce canopies.

\section{THE RESISTANCE APPROACH FOR TRITIUM TRANSFER ATMOSPHERE-SOIL-PLANT}

The driving equation for the transfer of HTO from atmosphere to leave is:

$$
\frac{d C}{d t}=\frac{V_{\text {exc }}}{M_{w}}\left(C_{\text {air }}-0.91 \rho_{s} C\right)+\frac{V_{\text {exc }}}{M_{w}}\left(\rho_{s}-\rho\right) C_{s}
$$

with:

$\mathrm{C}_{\mathrm{l}}-\mathrm{HTO}$ concentration in plant water (mainly leaf water) (Bq/kg); $\mathrm{C}_{\text {air }}-\mathrm{HTO}$ concentration in air $\left(\mathrm{Bq} / \mathrm{m}^{3}\right) ; \mathrm{C}_{\mathrm{s}}-\mathrm{HTO}$ concentration in the sap water (transpiration water), resulting from water extraction of roots at different depths $(\mathrm{Bq} / \mathrm{kg}) ; \rho_{\mathrm{s}}$ - saturated air humidity at vegetation temperature $\left(\mathrm{kg} / \mathrm{m}^{3}\right)$;

$\rho$ - air humidity at reference level $\left(\mathrm{kg} / \mathrm{m}^{3}\right) ; \mathrm{M}_{\mathrm{w}}-$ mobile water mass in vegetation leaves on a unit soil surface $(\mathrm{kg} / \mathrm{m} 2) ; \mathrm{V}_{\text {exc }}$ - exchange velocity atmosphere to canopy $(\mathrm{m} / \mathrm{s})$.

The above equation is used for all canopy, ignoring the transfer of air HTO to stream, as the exchange velocity is smaller with one order of magnitude. Initial diffusion of leaf water to steam is also ignored due to the slow velocity and the flushing of steam by sap flux with definitely less HTO concentration in the active phase. In the transition period, steam water and leaf water equilibrate gradually with root soil water and we ignored the details of this period for steams due to minor contribution to plant water concentration. The last term in equation (1) includes in fact the transpiration flux. In order to assess the HTO concentration in sap water, the tritium dynamics in soil and rooting characteristic must be known. At the soil surface we have:

$$
\frac{d C_{s w, 1}}{d t}=\frac{V_{e z, s}}{M_{w s}}\left(C_{a i r}-0.91 \rho_{s a t}\left(T_{s}\right) C_{s w, 1}\right)-D F
$$

where:

$\mathrm{C}_{\mathrm{sw}, 1}$ - HTO concentration in the first soil layer at the interface with in-canopy air $\mathrm{Bq} / \mathrm{kg}$

$\mathrm{V}_{\mathrm{ex}, \mathrm{s}}$ - exchange velocity in-canopy atmosphere to soil $(\mathrm{m} / \mathrm{s}) ; \rho_{\mathrm{sat}}\left(\mathrm{T}_{\mathrm{s}}\right)$ - saturated air humidity at soil surface temperature $\mathrm{kg} / \mathrm{m}^{3} ; \mathrm{M}_{\mathrm{ws}}$ - mass of water in the surface soil layer; DF- net flux of HTO at the bottom interface of the first soil layer

The exchage velocity form atmosphere to plant depends on canopy resistance, while the exchange velocity from atmosphere to soil depend s on soil resistance. We will discuss in more details both resistances.

\subsection{Soil resistance $\mathbf{R}_{S}$}

While for maximum possible exposure the soil-plant pathway has little contribution to the ingestion dose [1], for other situations it can contribute more than $50 \%$. The flux form atmosphere to soil strongly depends on so called "soil resistance", and semi-empirical quantity to avoid modeling of very complex processes. There is a tremendous amount of various expressions of soil resistance [3] spanning orders of magnitude and having limited applicability. To be able to have a more general parameterization, we analyzed experimental data obtained by Kondo [4] and observed some regularities linked with soil properties. Eventually we obtained a unique relationship as: 


$$
\mathrm{R}=\mathrm{R}_{\min }+\mathrm{R}_{\max } \exp \left\{\mathrm{A}\left[\left(\theta / \theta_{\mathrm{fc}}-\mathrm{B}\right) /(\mathrm{C}-\mathrm{B})\right]^{2}\right\}
$$

where:

$\theta$ - volumetric soil water fraction in upper $2 \mathrm{~cm}$; $\theta_{\mathrm{fc}}-$ field capacity; $\mathrm{R}_{\min }-$ minimum soil resistance, constant for all soil at $10 \mathrm{~s} / \mathrm{m}$; $R_{\max }$ - maximum soil resistance: near $3000 \mathrm{~s} / \mathrm{m}$ sand, $2000 \mathrm{~s} / \mathrm{m}$ pentru loam and $1500 \mathrm{~s} / \mathrm{m}$ for clay-Loam and vulcanic ash.

The constants in the formula show regularity in respect with soil texture and clay content.

$A=-7$, is constant for all soil types

$\mathrm{B}=0.11$ (sand), 0.074 (clay-loam), 0.03 (loam. Sandy loam, fine sand); 0.06 (volcanic ash),

$\mathrm{C}=1.3$ (sand), 0.95 (clay-loam), 0.75 (loam. Sandy loam, fine sand); 0.63 (volcanic ash),

The above parametrisation reproduces all data with a factor less than 2 (Figure 1 for Clay_Loam, Loam and SiltiSand) and when applied on independent data sets with a factor less than 3.

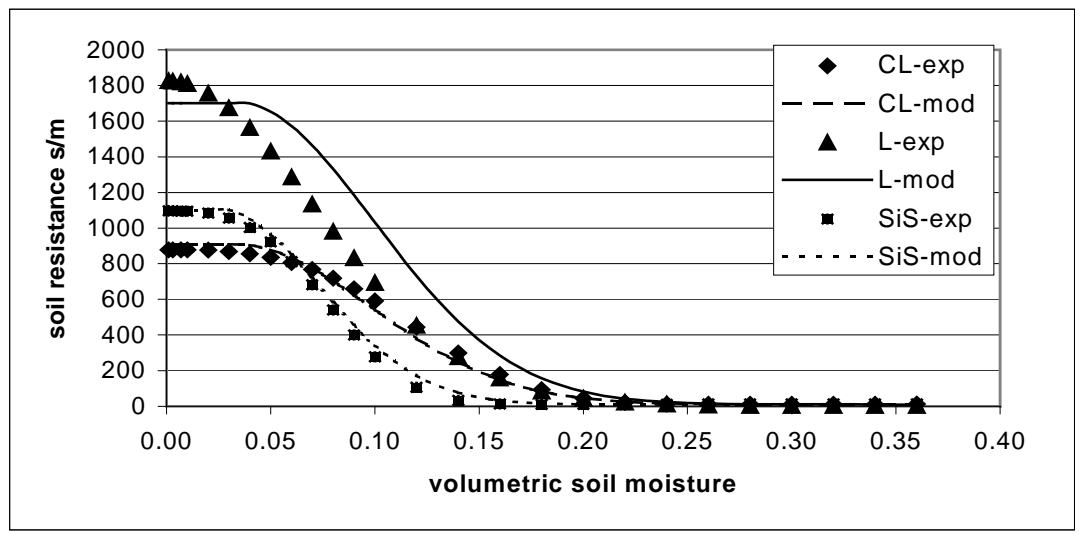

Figure 1. Model results and experimental data clay-loam, loam and Silty-sand.

\subsection{Canopy resistance}

In RODOS, we have abandoned the Jarvis classic parameterisation of leaf resistance and scaling to canopy, as it implies many unknown parameters for our 20 plants in all Europe.

We used the Jacobs-Calvet $[5,6]$ approach linking the leaf resistance with the photosynthesis. We start from the Jacobs-Goudriaan expresion for leaf resistance:

$$
R_{C}=\frac{C_{S}-C_{i}}{1.6 \circ A_{n}}, C_{i}=f\left(C_{s}-\Gamma\right)+\Gamma, f=f_{o}\left(1 .-D_{s} / D_{\max }\right)
$$

with

$\mathrm{C}_{\mathrm{s}}$ - and $\mathrm{C}_{\mathrm{i}}$ the $\mathrm{CO}_{2}$ concentration at leaf surface and leaf interior, $\Gamma$ - $\mathrm{CO}_{2}$ compensation point, $D_{s}$ - humidity deficit at leaf surfaces, $f_{0}$ and $D_{\max }$ - parameters describing the effect of humidity deficit on leaf resistance. $A_{n}$ - net leaf photosynthesis rate.

The full expression of leaf conductance, in the Jacobs formulation reads:

$$
g_{s c}+g_{c}=g_{c}+\frac{A_{n}-A_{\min } \cdot \frac{D_{s}}{D_{\max }} \cdot \frac{A_{g}}{A_{m, g}}+R_{d} \cdot\left(1-\frac{A_{g}}{A_{m, g}}\right)}{C_{s}-C_{i, v i r}}
$$

with:

$\mathrm{g}_{\mathrm{sc}}$ - stomatal conductivity for $\mathrm{CO}_{2}$; $\mathrm{g}_{\mathrm{c}}$ - cuticular conductivity; $\mathrm{A}_{\mathrm{n}}, \mathrm{A}_{\mathrm{g}}$ - net and gross photosinthetic rate; $A_{\text {min }}$ - residual cuticle photosinthetic rate; $A_{m, g}$ - maximum gross photosinthetic rate;

$\mathrm{R}_{\mathrm{d}}$-dark respiration rate. 
Working on this expression we used the well now relation $R_{d}=A_{m, g} / 9$ and we observed that $A_{\text {min }} \cong 4.7 / A_{m, g}$, using the initial Jacobs expressions and parameters. We obtain a condensed formula evidentiating the gross photosynthetic rate:

$$
g_{s c}=g_{c}+\frac{A_{g} \cdot\left(0.9-\frac{4.7}{A_{m, g}} \cdot \frac{D_{s}}{D_{\max }}\right)}{C_{s}-C_{i, v i r}}
$$

Finally, the water vapor conductance is obtained, with the correction due to evaporation, as in Jacobs [5].

In our context, we can ignore the variation of $\mathrm{CO}_{2}$ concentration in the canopy, affecting $\mathrm{C}_{\mathrm{s}}$, and we can integrate the above expression on the whole canopy height. This gives the canopy conductance as function of canopy gross photosynthetic rate. In spite of using the Jacobs leaf photosynthesis expression, with unknown plant specific parameters, we can now use the canopy gross photosynthetic rate as given in the WOFOST crop growth model when a large database for European crop exists [7]. The other parameters needed, namely $f_{0}$ and $D_{\max }$ are kept at recommended values for C3 and C4 plants. We have the following comparison between model results and observations of maximum stomata resistance:

Table 1. Comparision between experimental and theoretical data for maximum stomatal resistance.

\begin{tabular}{|l|l|l|l|}
\hline Plant type & Experimental val.(s/m) & Theoretical val (s/m) & References \\
\hline Wheat, vegetative stage & $41-52$ & 56 & Baldocchi, 1994 \\
\hline Wheat, anthesys & $62-100$ & 60 & Baldocchi, 1994 \\
\hline Maize, vegetative & $121-131$ & 111 & Baldocchi, 1994 \\
\hline Wheat & $17-20$ & 18 & Choudhury, 1998 \\
\hline Potatoe & $100-130$ & 130 & Vos, 1987 \\
\hline Alpha-alpha & $100-120$ & $110-130$ (dep. VPD) & Saugier, 1991 \\
\hline Soya & 66 & 70 & Oliosa, 1996 \\
\hline Grass C3 & 74 & $74-120$ (dep. VPD) & Knap, 1993 \\
\hline Grass C4 & 151 & $156-178$ (dep. VPD) & Knap, 1993 \\
\hline
\end{tabular}

The model results are close with experimental values, better than $50 \%$.

\subsection{OBT production in crops}

Photosynthesis rate and HTO concentration in plant water are driving the OBT production in crops [3]. With the improved model, as above, the experimental data on wheat [8] are satisfactory reproduced, without parameters' optimization.

Table 2. Comaparision between experimental data and model predictions for wheat.

\begin{tabular}{|l|l|l|l|l|l|l|}
\hline Time & \multicolumn{2}{l}{$\begin{array}{l}\text { Rel TWT at end } \\
\text { exposure \% }\end{array}$} & $\begin{array}{l}\text { TWT half time (1h after end) } \\
\text { min }\end{array}$ & REL OBT at harvest \% \\
\hline & Exp & Model & Exp & Model & Exp & Model \\
\hline DAWN & $26-74$ & $21-40$ & $40-60$ & $60-100$ & & 0.29 \\
\hline DAY & $53-100$ & $35-50$ & $20-49$ & $30-50$ & 0.23 & 0.36 \\
\hline DUSK & $20-26$ & $10-20$ & $230-600$ & $200-300$ & & 0.35 \\
\hline NIGHT & $18-19$ & $5-15$ & $?$ & $400-600$ & 0.27 & 0.36 \\
\hline
\end{tabular}

The model predicts lower uptake than experimental data. Partly this can be explained by the reference concentration: in the experiment the HTO concentration in air moisture was measured at canopy top, while in the model we considered it at a higher reference level. The model predictions must be corrected with the effect of atmospheric resistance and are increased by $40 \%$ in the day and near $10 \%$ in the night. The temperature difference between the experimental chamber and model explain most explain of the discrepancy in the uptake fraction. 


\section{EXTENSION OF SPARSE CANOPY APPROACH FOR TRITIATED WATER TRANSFER: THE CASE OF TWO LAYERS (SOIL-VEGETATION)}

In recent years the coupling between soil and canopy was more and more used in the frame of "sparse canopy" theory [9]. We have adapted the formalism for tritium uptake by plants, in order to investigate the usefulness for an operational radiological assessment model.

Using the partition between soil and vegetation in the sparse canopy approach (see Figure 2) we can write the equations for the concentration difference air-vegetation and air-soil as:

$$
F_{c}\left(R_{a a}+R_{a b}+R_{a c}\right)+F_{s} R_{a}=C_{a}-C_{c} ; F_{c} R_{a}+F_{s}\left(R_{a a}+R_{a s}+R_{s s}\right)=C_{a}-C_{s}
$$

where:

$\mathrm{C}_{\mathrm{a}}-\mathrm{HTO}$ concentration in air; $\mathrm{C}_{c}-\mathrm{HTO}$ concentration in vegetation; $\mathrm{C}_{\mathrm{s}}-\mathrm{HTO}$ concentration in soil; $R_{a a}$ - atmospheric resistance between reference level and canopy source height; $R_{a c}$ - boundary layer resistance; $\mathrm{R}_{\mathrm{sc}}$ - canopy resistance; Ras - atmospheric resistance between canopy source height and soil surface; $R_{s s}$ - soil resistance; $F_{c}$ - flux atmosphere - vegetation; $F_{s}$ - flux atmosphere - soil.

With the following notation, the solution is easy expressed:

$$
\frac{d C}{d t}=\frac{1}{M_{w}}\left\{F_{t r} C_{s}+V_{e x}\left[\left(C_{a}-0.91 \rho_{s} C\right)-\frac{R_{a a}}{R_{s}}\left(C_{a}-0.91 \rho_{s} C_{s a}\right)\right]\right\}
$$

where $\mathrm{F}_{\text {tr }}$ is the transpiration flux, $\mathrm{C}_{\mathrm{sa}}$ is the HTO concentration at the soil surface and

$$
V_{e x}=\frac{0.95 R_{1}}{R_{c}} ; R_{1}=\frac{R_{c} R_{s}}{R_{c} R_{s}-R_{a a}^{2}} ; R_{c}=R_{a a}+R_{a b}+R_{a c} ; R_{s}=R_{a a}+R_{a s}+R_{s s}
$$

Equation (8) is solved coupled with the equations describing the dynamics of HTO in soil [10], starting with the soil surface where the flux $F_{s}$ is used as boundary condition. The importance of coupling between the vegetation layer and the soil surface, intermediated by the in canopy air (see Figure 2), is ilustrated in Figure 3, for a wet and a dry soil surface and for plant canopy with a low (1) and high (5) Leaf Area Index.

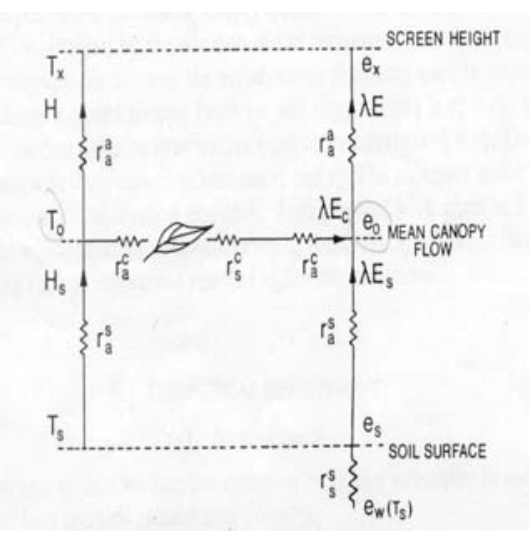

Figure 2. Schematic diagram of energy partition for sparse vegetation.

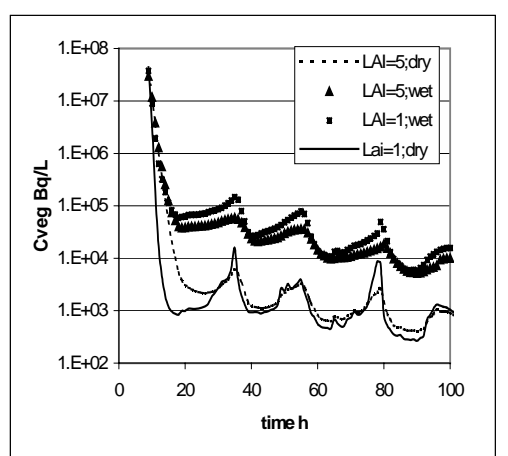

Figure 3. Vegetation HTO concentration in the sparse canopy approach.

In Figure 3 we observe that the coupling between soil surface and vegetation layer has a significant influence on canopy HTO concentration at both low and high Leaf Area Index, so more studies are justified. 


\section{DISCUSSION}

The Aiken List was divised in 1990 to help decide which transport processes should be investigated experimentaly as to derive the greatest improvement in performance of environmental tritium assessment models and was revised few years ago [1]. The importance of each process depends on case application. We tried to improve in this paper the modeling and soil canopy resistance and to have a preliminary study of the application of sparse canopy approach for the transfer of HTO in atmosphere-plant-soil continuum. Adapting Jacobs-Calvet model for stomatal conductance and combining with the WOFOST photosynthesis model and database, we are able to make reliable predictions for the dynamics of HTO and OBT in crops under the atmospheric forces. The new parametrisation for soil resintance offers more flexibility in various soil types. The extension of sparse canopy approach to HTO transfer reveals the role of vegetation-soil coupling and it needs further studies, in order to be included in operational codees. In the same time, it can give solutions for condensation dew and wet deposition for tritium transport. The present paper is not exhausting all possibilities of important processes for tritium transport.

\section{References}

[1] Raskob W., Barry P., Importance and Variability in Processes Relevant to Environmental Tritium Dose Assessment Models, JER, Vol. 136, pp.237-251, 1997.

[2] A. Melintescu, D. Galeriu, E. Marica, "Using WOFOST Crop Model for Data Base Derivation of Tritium and Terrestrial Food Chain Modules in RODOS”, P. C1-1241- C1-1246, Radioprotection, Numero special 37, C1, "The Radioecology - Ecotoxicology of Continental and Estuarine Environments ECORAD 2001”, 2002.

[3] D. Galeriu, A. Melintescu, C. Turcanu, W. Raskob, "FDMH - The Tritium Module in RODOS", Workshop on Environmental Behavior and Biological Effects of Tritium, 8- 9 May 2000, P.86, Kurri, Kumatori, Osaka, Japan, Ed. M. Saito, S. Kimura, and T. Takahashi ISSN 0287-0852 [KURRI-KR-61].

[4] Kondo J, Saigusa N and Sato T “A parameterization of evaporation from bare soil surfaces” J Apl Meteorol 29, 385.

[5] Jacobs C. M. J., Direct impact of atmospheric $\mathrm{CO}_{2}$ enrichment on regional transpiration, $\mathrm{PhD}$. Thesis, Agricultural University, Wageningen (1994).

[6] Calvet J. C., Agricultural and Forest Meteorology 103, 229 (2000)., Vol. 103, pp.229-247.

[7] Boogaard H. L, User's guide for the WOFOST 7.1 crop growth simulation model and WOFOST Control Center 1.5 Technical Document 52 DLO Vinand Staring Centre, Wageningen, 1998.

[8] Diabate, S. and Strack, S. "Organically bound tritium in wheat after short-term exposure to atmospheric tritium under laboratory condition”, Journal of Environmental Radioctivity, 1997, 67, 211.

[9] Wallace J.S., Verhoef A., Modelling interactions in mixed plant communities: ligt, water and carbon dioxide in Leaf Development and Canopy Growth, Edited by Bruce Marshall and Jeremy A. Roberts, 2001.

[10] Melayah A., Bruckler L., Modeling the transport of water stable isotopes in unsaturated soils under natural conditions, water Resources Research, Vol. 32, No. 7, pp.2047-2054, 1996. 